Electronic Physician (ISSN: 2008-5842)

http://www.ephysician.ir

March 2016, Volume: 8, Issue: 3, Pages: 2123-2128, DOI: http://dx.doi.org/10.19082/2123

\title{
Active listening: The key of successful communication in hospital managers
}

Vahid Kohpeima Jahromi ${ }^{1}$, Seyed Saeed Tabatabaee ${ }^{2}$, Zahra Esmaeili Abdar ${ }^{3}$, Mahboobeh Rajabi $^{4}$

${ }^{1}$ Social Determinants of Health Research Center, Institute for Futures Studies in Health, Kerman University of Medical Sciences, Kerman, Iran

${ }^{2}$ Medical Informatics Research Center, Institute for Futures Studies in Health, Kerman University of Medical Sciences, Kerman, Iran

${ }^{3}$ Alborz University of Medical Sciences, Karaj, Iran

${ }^{4}$ Health Services Management Research Center, Institute for Futures Studies in Health, Kerman University of Medical Sciences, Kerman, Iran

\section{Type of article: Original}

\begin{abstract}
Introduction: One of the important causes of medical errors and unintentional harm to patients is ineffective communication. The important part of this skill, in case it has been forgotten, is listening. The objective of this study was to determine whether managers in hospitals listen actively.

Methods: This study was conducted between May and June 2014 among three levels of managers at teaching hospitals in Kerman, Iran. Active Listening skill among hospital managers was measured by self-made Active Listening Skill Scale (ALSS), which consists of the key elements of active listening and has five subscales, i.e., Avoiding Interruption, Maintaining Interest, Postponing Evaluation, Organizing Information, and Showing Interest. The data were analyzed by IBM-SPSS software, version 20, and the Pearson product-moment correlation coefficient, the chi-squared test, and multiple linear regressions.

Results: The mean score of active listening in hospital managers was 2.32 out of 3 .The highest score (2.27) was obtained by the first-level managers, and the top managers got the lowest score (2.16). Hospital mangers were best in showing interest and worst in avoiding interruptions. The area of employment was a significant predictor of avoiding interruption and the managers' gender was a strong predictor of skill in maintaining interest ( $p<$ 0.05). The type of management and education can predict postponing evaluation, and the length of employment can predict showing interest $(\mathrm{p}<0.05)$.

Conclusion: There is a necessity for the development of strategies to create more awareness among the hospital managers concerning their active listening skills.

Keywords: active listening, communication, hospital managers
\end{abstract}

\section{Introduction}

Communication is one of the most important skills in life. This skill is not just speaking and writing; we often forget that one of the most important parts of it is listening. Listening is hard work and requires concentration (1). We do not listen efficiently because of our faulty listening habits. Listening is something more than the physical process of hearing. It is a matter of attitude and also an intellectual and emotional process (2). According to Hunsaker and Alessandra (1), when people are listening, they can be placed in one of four general categories, i.e., non-listener, marginal listener, evaluative listener, and active listener. Each category requires a particular depth of concentration and sensitivity from the listener, and trust and effective communication increase as we advance beyond the first type. Active listening (AL) is the highest and most effective level of listening, and it is a special communication skill. It is also a great strategy for having effective communication (3). It is based on complete attention to what a

\section{Corresponding author:}

Mahboobeh Rajabi, Health Services Management Research Center, Institute for Futures Studies in Health, Kerman University of Medical Sciences, Kerman, Iran.

Tel: +98.3432111511, Fax: +98.3432111613, E-mail: mrajabi5@yahoo.com

Received: September 07, 2015, Accepted: January 16, 2016, Published: March 2016

iThenticate screening: December 26, 2015, English editing: February 20, 2016, Quality control: February 26, 2016

(C) 2016 The Authors. This is an open access article under the terms of the Creative Commons Attribution-NonCommercialNoDerivs License, which permits use and distribution in any medium, provided the original work is properly cited, the use is non-commercial and no modifications or adaptations are made. 
person is saying, listening carefully while showing interest and not interrupting (4). Active listening requires listening for the content, intent, and feeling of the speaker. The active listener shows her or his interest verbally with questions and with non-verbal, visual cues signifying that the other person has something important to say (5). Active listening generally does not occur in hurried communications between two people (3). This skill included verbal and non-verbal items and as being a good active listener different factors should be considered, such as appropriate body movement and posture showing involvement, facial expressions, eye contact, showing interest in the speaker's words, minimum verbal encouragement, attentive silence, reflect back feelings and content, and summarizing intellectually the speaker's words and their purpose (6). Review of different texts and references showed that we can consider three principal factors for AL, i.e., listening attitude, listening skill, and conversation opportunity. According to these factors, we can consider five subscales for active listening, i.e., avoiding interruption, maintaining interest, postponing evaluation, organizing information, and showing interest (7-10). The role of communication skill, especially listening, is very important for managers, because listening is a critical factor in their effectiveness, and creative managers are good listeners. So, many organizations try to improve this skill in their managers $(11,12)$. Listening requires the managers to understand that their staff and customers are important. Managers listen to their staff's ideas and have the ability to draw out their best advice. It is certain when leaders allocate time to listen actively, they build trust and commitment in their work and this is different from one-way communication and issuing orders to people (13). Supervisors with better listening attitudes and skills enhance their communication with subordinates, which could result in the subordinates' perceiving that they have more support, which causes them to feel better about their work and their supervisor (14). Therefore, it is obvious that, if managers want to be successful, they should listen to their staff and customers and get their feedback (15). In management, AL is an important factor of the client-centered therapy developed by C. R. Rodgers (16). He brought into play AL for improving relationship between managers and workers in the organization. AL can improve interpersonal relationships and perception of confidence and respect, lessen tension, and provide a better environment for joint problem solving and sharing the information in organization (17). In a guideline in Japan, AL was introduced as an important factor for reducing uneasiness and suffering in workers, and it was used for managing workers' stress through improving communication (18). Changing interpersonal relationships positively and reducing stress by AL was reported by the National Institute for Occupational Safety and Health (NIOSH) (19). In healthcare organizations, improving communication among healthcare professional has a major impact on patients' safety since one of the important causes of medical errors and unintentional harm to patients is ineffective communication (20). The value of active listening has been generally known, but it has not been studied in depth, especially in healthcare. Although the root of active listening is in each person's personality, some factors or techniques can facilitate it and make it teachable (5). So, healthcare organizations can train and retrain their different levels of managers, making them more efficient and compassionate leaders, which will lead to a better work environment for the staff, making the organization more successful. Although calls for action issued by Keshtkaran, Makarem, and Motaghed (21-23) emphasized the need for organizations to conduct research in active listening in Iran, the literature shows that the results of such research has not been used productively in active listening, especially by hospital managers (24). Therefore, the aim of this study was to determine whether managers in hospitals listen actively. Moreover, since the listening styles between the top, middle, and first-level managers may vary according to their demographic features, we conducted additional analysis on managers' gender, age, education, marital status, positions, and the length of their employment.

\section{Material and Methods}

\subsection{Study setting and selection criteria}

This cross-sectional study was conducted between May and June 2014 in four teaching hospitals affiliated with the Kerman University of Medical Sciences in southeast Iran, including Shahid Beheshti, Afzalipor, Shahid Bahonar, and Shafa Hospitals. They had 220 to 460 active beds and 350 to 1000 personnel. The subjects included all 137 managers, consisting of four top managers, 94 middle managers and medical supervisors, and 39 first-level managers. All managers returned the questionnaire and 133 of them (97\%) completed all of the questions. We excluded four managers because they didn't complete the demographic part.

\subsection{Data collection and measurement tool}

Active Listening skill among hospital managers was measured by self-made Active listening Skill Scale (ALSS) developed based on a literature review (7-10). It consisted of 18 items with a 3-point Likert response option (usually, sometime, and seldom) with the key elements of active listening. It had five subscales, i.e., Avoiding Interruption, Maintaining Interest, Postponing Evaluation, Organizing Information, and Showing Interest. 


\subsection{Reliability and validity of measurement tool}

The validity of the content of the ALSS was explored by 10 organizational behavior and human resources management experts. The internal consistency of the ALSS sub-scales was calculated by Cronbach's alpha coefficient. Spearman's correlation coefficient was calculated to estimate the sub-scales' shared variance. The content validity of the ALSS was good and internal consistency was 0.70 .

\subsection{Data analysis}

The data were analyzed using descriptive and inferential statistics (Pearson product-moment correlation coefficient, chi-squared test, and Multiple Linear Regression) through IBM-SPSS 20, and the significance level was set to 0.05 .

\subsection{Ethical consideration}

Managers were asked to complete the ALSS questionnaires anonymously. This study was approved and supported by the Kerman University of Medical Sciences. Also it received the approval of the Ethics Committee of the University.

\section{Results}

\subsection{Demographic and professional characteristics of managers}

Most of managers $(70 \%)$ were female, $86 \%$ were married, and their mean age was $39 \pm 7.6$ (24-57). Of 133 managers, $93(70 \%)$ worked in clinical units, and 40 (30\%) worked in administrative units. Most of them (76\%) had a license degree and at least 16 years of experience (Table 1).

Table 1. Demographic and professional characteristics of the managers

\begin{tabular}{|l|l|l|}
\hline Managers Characteristics & n (\%) \\
\hline Gender & Male & $40(30)$ \\
\cline { 2 - 3 } & Female & $93(70)$ \\
\hline \multirow{4}{*}{ Age (years) } & $20-30$ & $23(17)$ \\
\cline { 2 - 3 } & $31-40$ & $54(41)$ \\
\cline { 2 - 3 } & $>40$ & $56(42)$ \\
\hline \multirow{5}{*}{ Education level } & Diploma & $13(10)$ \\
\cline { 2 - 3 } & Undergraduate & $101(76)$ \\
\cline { 2 - 3 } & Graduate & $15(11)$ \\
\cline { 2 - 3 } & GP & $4(3)$ \\
\hline \multirow{3}{*}{ Larital status } & Married & $115(86)$ \\
\cline { 2 - 3 } & Single & $18(14)$ \\
\hline \multirow{5}{*}{ Area of Emplh of Employment (years) } & $<10$ & $38(29)$ \\
\cline { 2 - 3 } & $1-20$ & $57(42)$ \\
\cline { 2 - 3 } & $>20$ & $38(29)$ \\
\hline & Clinical & $40(30)$ \\
\cline { 2 - 3 } & health-administration & $40)$ \\
\hline
\end{tabular}

\subsection{Descriptive analysis of active listening and its subscales}

The active listening mean score in hospital managers was 2.32 out of 3 (Min $=1.94$, Max $=2.72)$. Hospital mangers were best in showing interest skill (Mean $=2.4, \mathrm{SD}=0.34$ ) of $\mathrm{AL}$, although they were worst in avoiding interruption skill $($ Mean $=2.05, \mathrm{SD}=0.37)$. Among the $\mathrm{AL}$ subscales, the highest score was obtained by first-level managers $($ Mean $=2.27, \mathrm{SD}=0.36)$, and the top managers got the lowest score $($ Mean $=2.16, \mathrm{SD}=0.31)($ Table 2$)$.

Table 2. Comparison of active listening and its subscales between three levels of managers

\begin{tabular}{|l|l|l|l|l|l|l|}
\hline Level of managers & Total & $\mathrm{MI}^{1}$ & $\mathrm{PE}^{2}$ & $\mathrm{OI}^{3}$ & $\mathrm{SI}^{4}$ & $\mathrm{AI}^{5}$ \\
\hline Top Manager & $2.16 \pm 0.31$ & $2.2 \pm 0.35$ & $2.1 \pm 0.19$ & $2.2 \pm 0.35$ & $2.2 \pm 0.35$ & $2.1 \pm 0.33$ \\
\hline Middle Manager & $2.24 \pm 0.33$ & $2.2 \pm 0.33$ & $2.2 \pm 0.36$ & $2.3 \pm 0.32$ & $2.5 \pm 0.32$ & $2.03 \pm 0.32$ \\
\hline First Level Manager & $2.27 \pm 0.36$ & $2.2 \pm 0.32$ & $2.3 \pm 0.43$ & $2.4 \pm 0.33$ & $2.5 \pm 0.34$ & $2.03 \pm 0.39$ \\
\hline
\end{tabular}

1: Maintaining Interest, 2: Postponing Evaluation, 3: Organizing Information, 4: Showing Interest, 5: Avoiding Interruption; the numbers are presented in Mean $\pm \mathrm{SD}$ 


\subsection{Analysis of active listening and demographic characteristics relationships}

The area of employment was a significant predictor of avoiding interruption, as health-administrators achieved higher scores than clinical $(\beta=0.316, p=0.002)$. Managers' gender also influenced their maintaining interest skill, with female managers being better at it $(\beta=-0.256, p=0.011)$. Type of management $(\beta=-0.167, p=0.04)$ and education $(\beta=-0.195, p=0.03)$ were significant predictors of postponing evaluation. So, first-level managers rather than top managers and managers with lower levels of education were more skilled at postponing evaluation. Also for showing interest skill, length of employment $(\beta=0.42, p=0.009)$ was a significant predictor, and increases in the time of employment can make managers better at this skill. The other characteristics of the respondents were the same (Table 3).

Table 3. Linear Regression analysis for predicting AL Subscale

\begin{tabular}{|c|c|c|c|c|c|}
\hline AL subscales & Characteristic & $\mathrm{b}$ & SEb & $\beta$ & $\mathrm{p}$ \\
\hline \multirow{7}{*}{$\begin{array}{l}\text { Avoiding } \\
\text { Interruption } \\
\left(\mathrm{R}^{2}=0.03\right)\end{array}$} & Age (years) & 0.012 & 0.080 & 0.023 & 0.885 \\
\hline & Length of employment (years) & -0.040 & 0.077 & -0.081 & 0.608 \\
\hline & Gender $(\mathrm{F} / \mathrm{M})$ & 0.119 & 0.079 & 0.148 & 0.135 \\
\hline & Marital status (yes/no) & 0.085 & 0.099 & 0.079 & 0.389 \\
\hline & Area of employment (health-administration, clinical) & 0.254 & 0.080 & 0.316 & 0.002 \\
\hline & Type of management (first, middle, top) & 0.022 & 0.065 & 0.032 & 0.731 \\
\hline & Level of education (Diploma, ... ) & -0.058 & 0.059 & -0.089 & 0.329 \\
\hline \multirow{7}{*}{$\begin{array}{l}\text { Maintaining } \\
\text { Interest } \\
\left(\mathrm{R}^{2}=0.01\right)\end{array}$} & Age (years) & -0.030 & 0.072 & -0.068 & 0.673 \\
\hline & Length of employment (years) & 0.013 & 0.069 & 0.030 & 0.850 \\
\hline & Gender (F/M) & -0.182 & 0.071 & -0.256 & 0.011 \\
\hline & Marital status (yes/no) & 0.045 & 0.088 & 0.047 & 0.614 \\
\hline & Area of employment (health-administration, clinical) & -0.014 & 0.072 & -0.020 & 0.844 \\
\hline & Type of management (first, middle, top) & 0.045 & 0.058 & 0.074 & 0.435 \\
\hline & Level of education (Diploma, ... ) & -0.054 & 0.053 & -0.094 & 0.308 \\
\hline \multirow{7}{*}{$\begin{array}{l}\text { Postponing } \\
\text { Evaluation } \\
\left(\mathrm{R}^{2}=0.06\right)\end{array}$} & Age (years) & 0.117 & 0.086 & 0.212 & 0.176 \\
\hline & Length of employment (years) & -0.016 & 0.082 & -0.030 & 0.845 \\
\hline & Gender (F/M) & -0.053 & 0.085 & -0.060 & 0.532 \\
\hline & Marital status (yes/no) & 0.004 & 0.105 & 0.004 & 0.968 \\
\hline & Area of employment (health-administration, clinical) & 0.024 & 0.086 & 0.028 & 0.777 \\
\hline & Type of management (first, middle, top) & -0.126 & 0.069 & -0.167 & 0.042 \\
\hline & Level of education (Diploma, ... ) & -0.138 & 0.063 & -0.195 & 0.031 \\
\hline \multirow{7}{*}{$\begin{array}{l}\text { Organizing } \\
\text { Information } \\
\left(\mathrm{R}^{2}=-0.005\right)\end{array}$} & Age (years) & 0.017 & 0.074 & 0.037 & 0.820 \\
\hline & Length of employment (years) & 0.017 & 0.071 & 0.038 & 0.813 \\
\hline & $\operatorname{Sex}(\mathrm{F} / \mathrm{M})$ & -0.056 & 0.073 & -0.077 & 0.441 \\
\hline & Marriage status (yes/no) & 0.079 & 0.091 & 0.081 & 0.388 \\
\hline & Area of employment (health-administration, clinical) & -0.041 & 0.074 & -0.056 & 0.581 \\
\hline & Type of management (first, middle, top) & -0.052 & 0.060 & -0.083 & 0.386 \\
\hline & Level of education (Diploma, ... ) & -0.091 & 0.054 & -0.156 & 0.094 \\
\hline \multirow{7}{*}{$\begin{array}{l}\text { Showing } \\
\text { Interest } \\
\left(\mathrm{R}^{2}=0.017\right)\end{array}$} & Age (years) & -0.139 & 0.075 & -0.297 & 0.066 \\
\hline & Length of employment (years) & 0.190 & 0.072 & 0.421 & 0.009 \\
\hline & Gender (F/M) & -0.053 & 0.074 & -0.071 & 0.472 \\
\hline & Marital status (yes/no) & 0.034 & 0.092 & 0.034 & 0.716 \\
\hline & Area of employment (health-administration, clinical) & -0.032 & 0.075 & -0.042 & 0.675 \\
\hline & Type of management (first, middle, top) & -0.054 & 0.060 & -0.085 & 0.370 \\
\hline & Level of education (Diploma, ... ) & 0.035 & 0.055 & 0.059 & 0.523 \\
\hline
\end{tabular}

\section{Discussion}

In our study, the active listening mean score of hospital managers was 2.32 out of 3 . Top managers in the hospitals were weaker in AL skill in than the first-level and middle managers, which might contribute to their eventful work and lack of training. Some studies have shown that most people are poor listeners (25). In a study by Atwater (15), more than $85 \%$ were average or worse in AL. In addition, listening studies in managers have displayed that their 
listening skill and Al skill were not excellent, which was in agreement with our findings (21). The Kubota study in Japan showed that the middle managers' AL score was 18.7 (out of 30 ), and $52.5 \%$ of them attained the medium score (11). In the AL subscales, hospital managers got the best score in showing interest skill and organizing information and the worst in avoiding interruptions. Showing interest is a great skill because managers by showing attention to the staff speaking excite them reveals their hidden ideas or their work related problems. It also helps staff become closer to their managers and perceive them as kind managers. In this study, managers were worst in avoiding interruption skill of AL. People need time to explore their thoughts and feelings, so by being silent, the speaker is allowed to continue speaking or looking for ideas. Silence is also helpful in preventing impairing and unnecessary interaction. Nevertheless, the managers in this study did not pay attention to this issue. The results showed that employment area can predict avoiding interruption, as health-administrator achieved higher score than clinical. This can be related to the health administrators' educational field or special training. Female managers' AL skill was higher than that of male managers, which is congruent with previous studies (26). Managers' gender also can influence their maintaining interest skill, and female managers were more skillful in this area. Types of management and education level were predictors of postponing evaluation skill. So, supervising in the first level of organization and having lower education affected positively the postponing evaluation skill. Length of employment was a significant predictor of showing interest and increases in length of employment can make managers be better in this skill. It may be manager experiences showed them that staff ideas or solutions can be so helpful in organizational problems, and this caused them to be more interested in hearing them and getting their ideas. Even though AL skill in hospital managers is associated with patients exposing their concerns (27) and is the first step towards patient-centered healthcare (28) and providing better work conditions for nurses and other staff members, comparatively few managers have received training regarding effective listening (26). Hunsaker and Alessandra recommended that organizations learn AL skills to conquer their barriers (1). Therefore, it seems that using active listening in managerial communication can be very helpful in creating better work environments. Also, awareness and knowledge of the barriers, as well as the motivation to overcome them, are valuable for managers in organizations. As a limitation, the managers' high workloads and lack of time for completing the questionnaire prolonged this study.

\section{Conclusions}

The findings showed hospitals first-level and middle managers were better than top managers in AL skill. In AL subscales, hospital managers got the best score in showing interest skill and organizing information and the worst in avoiding interruption skill. Area of employment and managers' gender were the significant predictors of avoiding interruption and maintaining interest skill. Type of management and education can predict postponing evaluation and length of employment can predict showing interest. Active listening does not come naturally to most of us, and, like other communication skills, it must be learned and developed. So, there is a necessity for the development of strategies to create more awareness among hospital managers regarding the AL skill. Moreover, further research also should be focused on the development of interpersonal and communication skills among healthcare managers.

\section{Acknowledgments:}

This paper was derived from a research project that was approved and financially supported by the Vice Chancellor for Research at Kerman University of Medical Sciences (project no: 92/10/60/37641). The authors are sincerely grateful for the Vice Chancellor's assistance as well as the assistance of all of the managers at Kerman teaching hospitals.

\section{Conflict of Interest:}

There is no conflict of interest to be declared.

Authors' contributions:

All authors contributed to this project and article equally. All authors read and approved the final manuscript.

\section{References:}

1) Hunsaker PL, Alessandra T, Alessandra AJ. The new art of managing people, updated and revised: Personto-person skills, guidelines, and techniques every manager needs to guide, Direct, and Motivate the Team. 2008. Simon and Schuster Inc. New York NY, USA.

2) Jones JE, Pfieffe JW. The 1974 Annual Handbook for Group Facilitators, San Diego, CA: Pfieffer. 1974. In Small Group Instructor Training Course (SGITC). 1998. By U. S. Army. 
3) Gonzalez TD. Impact of active listening training at a California state hospital: a quantitative study. [PhD thesis]. 2009. University of Phoenix, Arizona, USA.

4) Weger HJR, Castle GR, Emmett MC. Active listening in peer interviews: the influence of message paraphrasing on perceptions of listening skill.. International Journal of Listening. 2010; 24: 34-49. doi: 10.1080/10904010903466311.

5) Bauer C, Kathrin F, Renate MP. Introducing "active listening" to instant messaging and e-mail: benefits and limitations. IADIS International Journal on WWW/Internet. 2010; 7(2): 1-17.

6) Robertson K. Active listening: more than just paying attention. Aust Fam Physician. 2005; 34(12): 1053-5. PMID: 16333490.

7) Harvard Manage Mentor-coaching tools. Active Listening Self-Assessment. 2004. Available from: http://www.mheducation.ca/college/mcshane4/student/olc/4obm_sa_08.html.

8) Canadian Career Development Foundation. Circuit Coach, Helping Youth Get Ready/Self B.1.2 Active Listening. Available from: http://www.ccdf.ca/ccdf/NewCoach/english.

9) McShane SL. Canadian organization behavior, chapter 8: Communicating in organizational settings, 2000. Mcgraw-hill, Ryerson. Toronto.

10) Mishima N, Kubota S, Nagata S. The development of a questionnaire to assess the attitude of active listening. J Occup Health. 2000; 42(3): 111-8. doi: 10.1539/joh.42.111.

11) Kubota S, Mishima N, Nagata S. A study of the effects of active listening on listening attitudes of middle managers. J Occup Health. 2004; 46(1): 60-7. doi: 10.1539/joh.46.60, PMID: 14960831.

12) Keyser J. Active listening leads to business success. ATD. 2013; 67(7): 26-8.

13) Cohen S, Eimicke WB. The new effective public manager: Achieving success in a changing government. 1995. Jossey-Bass. San Francisco. USA.

14) Minema S, Tsutsumi A, Takao S, Nishiuchi K, Kavakami N. Supervisors' attitude and skills for active listening with regard to working conditions and psychological stress reactions among subordinate workers. J Occup Health. 2007; 49(2): 81-7. PMID: 17429164.

15) Atwater E. I Hear you: A listening skills handbook. 1992. Walker \& Co; Rev Sub edition. New York. USA.

16) Rogers CR. Client-centered therapy: Its current practice, implications and theory. 1951. Constable. London.

17) Salem R. Empathic listening. Beyond intractability. Eds. Guy Burgess and Heidi Burgess. Conflict information consortium. 2003. University of Colorado, Boulder, Colorado, USA.

18) The text book for mental health promotion to workers - guideline and its explanation-Tokyo: JISHA (2001). Japan Industrial Safety and Health Association: 31-5.

19) National Institute for Occupational Safety and Health. Available from: http://www.medscape.com/ partners/niosh/public/niosh.

20) Leonard M, Graham S, Bonacum D. The human factor: the critical importance of effective teamwork and communication in providing safe care. Qual Saf Health Care. 2004; 13(Suppl 1): i85-i90. doi: 10.1136/qshc.2004.010033, PMCID: PMC1765783.

21) Keshtkaran A, Heidari A, Bastani P. Study of managers' communication skills based on the staff's view in shiraz university of medical sciences. payavard. 2012; 5(4): 41-8.

22) Makarem A, Movaffaghi Z, Hosseini F, Beyraghi N, Nabavi F, Khajedaluee M. Clinical Medical Teachers' Competency of Active Listening in Mashhad University of Medical Sciences. Iranian Journal of Medical Education.. 2013, 12(12): 935-46

23) Motaghed Larijani Z, Vakili M, Gofranipour F, Mirmohammadkhani M. Effects of health education program on Behvarz's interpersonal communication skills in Semnan University of Medical Sciences. koomesh. 2015; 16(2): 229-38.

24) Baghiyani Moghadam M, Momayyezi M, Rahimdel T. Communication Skills of department heads in shahidsadoughi university of medical sciences. Iranian Journal of Medical Education. 2012; 12(6): 448-57.

25) Axley SR. Communication at work: Management and the communication-intensive organization. 1996. Westport, Conn: Quorum Books, USA.

26) Khanifar H, Jandaghi G, Shariati F, Zarvandi N. Reviewing the communicative role of effective listening and commitment. Journal of Human Resource Management Research. 2009; 1(3): 147-70.

27) Wissow LS, Wilson ME, Roter DL. Pediatrician interview style and mothers' disclosure of psychosocial issues. Pediatrics. 1994; 93(2): 289-95. PMID: 8121743.

28) Fassaert T, van Dulmen S, Schellevis F, Bensing J. Active listening in medical consultations: development of the active listening observation scale (ALOS-global). Patient Educ Couns. 2007; 68(3); 258-64. PMID: 17689042 . 